\title{
A reporting protocol for thermochronologic modeling illustrated with data from the Grand Canyon
}

\author{
Rebecca M. Flowers ${ }^{1 *}$, Kenneth A. Farley ${ }^{2}$, Richard A. Ketcham ${ }^{3}$ \\ ${ }^{1}$ Department of Geological Sciences, University of Colorado, Boulder, Colorado, USA \\ ${ }^{2}$ Division of Geological and Planetary Sciences, Pasadena, California, USA \\ ${ }^{3}$ Jackson School of Geosciences, University of Texas, Austin, Texas, USA \\ * To whom correspondence should be addressed: \\ Email: rebecca.flowers@colorado.edu,Phone: 303-492-5135
}

Originally submitted to Earth and Planetary Science Letters: March 18, 2015

Revised version submitted: July 31, 2015

Second revised version submitted: September 29, 2015

\section{Abstract}

Apatite (U-Th)/He and fission-track dates, as well as ${ }^{4} \mathrm{He} /{ }^{3} \mathrm{He}$ and fission-track length data, provide rich thermal history information. However, numerous choices and assumptions are required on the long road from raw data and observations to potentially complex geologic interpretations. This paper outlines a conceptual framework for this path, with the aim of promoting a broader understanding of how thermochronologic conclusions are derived. The tiered structure consists of thermal history model inputs at Level 1, thermal history model outputs at Level 2, and geologic interpretations at Level 3. Because inverse thermal history modeling is at the heart of converting thermochronologic data to interpretation, for others to evaluate and reproduce conclusions derived from thermochronologic results it is necessary to publish all data required for modeling, report all model inputs, and clearly and completely depict model outputs. Here we suggest a generalized template for a model input table with which to arrange, report and explain the choice of inputs to thermal history models. Model inputs include the thermochronologic data, additional geologic information, and system- and model-specific parameters. As an 
32 example we show how the origin of discrepant thermochronologic interpretations in the

33 Grand Canyon can be better understood by using this disciplined approach.

\section{1. Introduction}

36 Low temperature thermochronology has advanced rapidly over the last two

37 decades. The combination of apatite (U-Th)/He (AHe) and ${ }^{4} \mathrm{He} /{ }^{3} \mathrm{He}$ dating, along with

38 apatite fission-track (AFT) dates and fission-track length (FTL) distributions, together

39 characterize the migration of a rock sample through temperatures from $\sim 120-30^{\circ} \mathrm{C}$. The

40 uniquely low temperatures accessible through these systems has led to an abundance of

41 studies documenting the cooling and heating of rocks in the upper few kilometers of the

42 Earth's crust, as well as established a quickly expanding user base of these techniques

43 (see Reiners \& Ehlers, 2005). The wealth of thermal information available from these

44 combined systems, and the number and variety of measurements and geologic

45 observations that are brought to bear in a given study, increasingly demand sophisticated

46 models to derive accurate and defensible geologic interpretations. However, the path

47 from observation to geologic interpretation is long, and in many studies it is difficult to

48 understand all the steps, choices, and assumptions made along the way. As a result, it is

49 frequently challenging to assess an interpretation's robustness, understand why and how

50 it was developed, and determine how it can be refined or tested.

51 In this paper we propose a protocol for organizing and reporting the information

52 necessary for thermochronologic modeling. Our objective is to enhance understanding of

53 how thermochronologic interpretations are obtained. The concepts here have strong

54 synergy with ongoing efforts to archive geochronologic measurements, but are focused at 
55 a higher interpretive level. The suggested template can not only help guide new users of

56 thermochronologic methods in deriving robust interpretations of their own datasets, but

57 also, if adopted, would help clarify the origin of interpretations in specific studies and

58 better focus future work. Our interest in these issues first arose from recent studies that

59 yield disputed interpretations of the antiquity of the Grand Canyon (Flowers \& Farley,

60 2012, 2013; Karlstrom et al., 2014). The quantity and diversity of observations brought to

61 bear on this problem, and the complexity of the modeling involved, illustrate how

62 difficult it can be to identify the source of contrasting conclusions. We first outline a

63 conceptual structure for the path from data to geologic interpretation, then discuss the

64 building blocks of this hierarchy by reviewing the methodologies involved, propose a

65 generalized model input reporting protocol, and provide an illustration using the Grand

66 Canyon.

67

\section{Data Levels: From Data to Geologic Interpretation}

Figure 1 offers a structure by which to construct a rigorous path of argument

70 extending from thermochronologic observations to sophisticated geologic interpretations.

71 We adopt a scheme in which there are multiple data levels, advancing from rawer data

72 and simpler observations to data products that include increasing interpretation by linking

73 elements derived from the previous level. By defining all elements within this tiered

74 framework it becomes possible to analyze the argumentation, identify the source of

75 differences among competing interpretations arising from the same or related data, and

76 investigate how each element contributes to the interpretation. This interpretational

77 hierarchy is adapted from the data levels used by NASA and EarthScope (e.g., Gurnis et 
78 al., 2012), although we do not employ their strict definitions of unprocessed and derived

79 data at different levels. Rather we modify this approach for our context in the manner

80 described below.

81 Level 1 of the framework consists of model input, which can be subdivided into

82 three broad categories: thermochronologic data, additional geologic information, and

83 system-specific and model-specific parameters. Broadly speaking, thermochronologic

84 data can be seen as consisting of the totality of the measurements, from isotopic and

85 elemental compositions to fission-track lengths and step-heating spectra, and

86 documentation of how they were made and processed into derived quantities such as

87 dates. This category may be taken to correspond to the information that would be entered

88 into a database of geochemical and/or geochronologic data resulting from community

89 efforts for a given technique. In addition, this category includes which measurements are

90 selected and/or combined for including in the model. Additional geologic information

91 consists of independent data that result in direct model input, such as depositional age

92 and temperature, and non-modeled ages such as zircon $\mathrm{U} / \mathrm{Pb}$. This category also may

93 include explicit assumptions being made and hypotheses being tested, such as the timing

94 of peak heating. Finally, system- and model-specific parameters include the kinetic

95 models used for thermal history modeling, the modeling code, and input specific to that

96 modeling code such as statistical fitting criteria or algorithm parameters. Note that many

97 of these model inputs are derived from still rawer data using basic assumptions and

98 physical models (examples of inputs to He and AFT data in Figure 1).

99 Level 2 of the framework includes the output (allowed tT paths) of an inversion

100 model developed with and honoring the Level 1 inputs. Thus each Level 1 element can be 
101 viewed as a building block for a Level 2 result - by linking together different Level 1

102 elements, different Level 2 results may be obtained. At Level 2 the allowed tT paths can

103 then be horizontally integrated with additional geologic observations and assumptions to

104 achieve the geologic interpretations at Level 3.

105 In the next section we provide a brief overview of the relevant methods. We

106 confine our discussion here to apatite, as the most-studied and best-characterized mineral

107 of both the (U-Th)/He and fission-track systems. Extensive reviews of both AHe and

108 AFT exist (e.g., Donelick et al., 2005; Reiners and Ehlers, 2005); our goal here is only to

109 motivate and explain aspects of the methods that are critical to accurate thermal history

110 modeling and thus are important Level 1 elements.

\section{3. Underpinnings of Low Temperature Thermochronology}

\section{$113 \quad 3.1$ The apatite (U-Th)/He system}

114 AHe chronometry is based on $\alpha$ decay of $\mathrm{U}, \mathrm{Th}$, and Sm. Over geologic

115 timescales He is strongly retained in apatite at Earth surface conditions, but is rapidly lost

116 via thermally-activated volume diffusion at temperatures above $\sim 100^{\circ} \mathrm{C}$. A reference

117 point for understanding cooling dates is provided by the closure temperature (Dodson,

118 1973), which for the $\mathrm{AHe}$ system varies from $\sim 55$ to $>100^{\circ} \mathrm{C}$ depending on radiation

119 damage, grain size, and cooling rate. AHe dates are derived from measurements of the

120 parent and daughter abundances in an entire crystal. The apatite ${ }^{4} \mathrm{He} /{ }^{3} \mathrm{He}$ method is a

121 variant in which the ${ }^{4} \mathrm{He}$ concentration profile is characterized. The utility of this method

122 is that the concentration profile documents the degree of diffusional rounding of ${ }^{4} \mathrm{He}$ in

123 the sample, which is sensitive to the apatite's temperature history (Shuster and Farley, 
124 2003). An apatite's bulk He concentration is simply the integral of this profile over the

125 entire crystal. Thus bulk dates and ${ }^{4} \mathrm{He} /{ }^{3} \mathrm{He}$ spectra are not completely independent

126 observations - rather the ${ }^{4} \mathrm{He} /{ }^{3} \mathrm{He}$ method provides insight into how the bulk date was

127 developed.

128 Alpha particles travel $\sim 20 \mu \mathrm{m}$ after parent decay, and this distance is often a

129 significant fraction of the size of an apatite crystal. When an apatite's surroundings have

130 negligible parent concentrations compared to the apatite itself, the net result is $\alpha$-ejection.

131 Given a crystal's size and geometry, this effect can be modeled (e.g., Farley et al., 1996;

132 Hourigan et al., 2005; Ketcham et al., 2011). Most AHe dates are corrected for this effect

133 assuming a hexagonal prism geometry. However, the accuracy of this correction is

134 increasingly suspect as grain size decreases and the correction's magnitude increases.

135 Regardless of whether a correction is made, $\alpha$-ejection modifies the shape of the ${ }^{4} \mathrm{He}$

136 profile, and thus affects the diffusional loss rate. In some cases the assumption of

137 negligible parent concentration surrounding an apatite is violated, leading to $\mathrm{He}$

138 implantation and erroneously old and often highly scattered He dates. Because analyzed

139 apatites carry no record of their neighborhood, He dates cannot generally be corrected for

140 this effect (Murray et al., 2014; Spiegel et al., 2009).

141 Zonation of parent nuclides is an additional consideration. Zonation matters

142 because it affects the $\alpha$-ejection correction, modifies the ${ }^{4} \mathrm{He}$ concentration profile on

143 which diffusion acts and which the ${ }^{4} \mathrm{He} /{ }^{3} \mathrm{He}$ method documents, and likely contributes,

144 via heterogeneous radiation damage accumulation, to variation in diffusion kinetics

145 within a grain (Farley et al., 2011). In some cases, particularly for studies using the

$146{ }^{4} \mathrm{He} /{ }^{3} \mathrm{He}$ method, parent nuclide distribution is measured using laser ablation ICPMS 
147 (Farley et al., 2011; Johnstone et al., 2013).The measured distribution must be converted

148 into an appropriate representation of the distribution within the three-dimensional grain

149 (e.g., Farley et al., 2011). Since the ${ }^{4} \mathrm{He} /{ }^{3} \mathrm{He}$ spectrum is very sensitive to zonation

150 (Farley et al., 2010), apatites with extreme zonation (which is difficult to constrain by

151 limited LA-ICPMS data), are inappropriate for ${ }^{4} \mathrm{He} /{ }^{3} \mathrm{He}$ work. He dates are not strongly

152 affected by typical apatite zonation magnitudes (Ault and Flowers, 2012). In the absence

153 of a measured parent nuclide distribution, analysts commonly assume homogeneity.

154 Ideally, apatite grains selected for AHe dating are complete and euhedral, but in

155 practice such grains may not be available, and rounded grains or fragments are used.

156 This can introduce additional uncertainty that is difficult to quantify due to breakage

157 effects on the diffusion domain size and the $\alpha$-ejection correction, especially if the timing

158 of abrasion or breakage is unknown (Brown et al., 2013).

159 Acquisition of an AHe date involves selection of individual inclusion-free apatite

160 crystals, crystal dimension measurement, He degassing and analysis, apatite dissolution,

161 and U, Th, and Sm analysis by ICPMS. The grain dimensions constrain the size of the

162 diffusion domain (usually converted into an equivalent spherical radius) and the

163 magnitude of the $\alpha$-ejection correction. Most labs report single-grain AHe dates with

164 errors that include the propagated uncertainties on the parent and daughter abundances

165 (typically a few \%), but may or may not include the uncertainty in the $\alpha$-ejection

166 correction, and cannot include effects that are unmeasured, unknown, or unquantifiable,

167 such as implantation, zoning or fragmentation. Some labs instead report a blanket

168 uncertainty based on repeated measurements of standards. It is frequently useful to

169 combine parent nuclide abundances into a single quantity that approximates the total $\alpha$ - 
170 production, which is a proxy for the amount of radiation damage accumulated in an

171 apatite not experiencing annealing. This quantity is known as "effective uranium" (eU,

172 where $\mathrm{eU}=\mathrm{U}+0.235 \mathrm{Th}$ in $\mathrm{ppm}$; Sm contributes too little to require inclusion in this

173 approximation).

$174 \quad \mathrm{The}{ }^{4} \mathrm{He} /{ }^{3} \mathrm{He}$ method is analytically complex and therefore less commonly

175 applied. In this method, ideally whole, euhedral apatites are irradiated with energetic

176 protons to create a uniform distribution of ${ }^{3} \mathrm{He}$ via spallation, and then subjected to a step-

177 heating experiment in which the evolved ${ }^{4} \mathrm{He} /{ }^{3} \mathrm{He}$ ratio is measured. The ${ }^{4} \mathrm{He} /{ }^{3} \mathrm{He}$

178 spectrum (i.e., the measured ratio as a function of the cumulative amount of ${ }^{3} \mathrm{He}$ evolved)

179 is related to the ${ }^{4} \mathrm{He}$ concentration profile within the grain. The ${ }^{4} \mathrm{He} /{ }^{3} \mathrm{He}$ spectrum can be

180 converted into an age spectrum by normalizing to the ${ }^{4} \mathrm{He}$ concentration profile produced

181 by $\alpha$-ejection alone, and to the sample's AHe date (Shuster and Farley, 2005).

182 Knowledge of He diffusion kinetics is critical to the interpretation of AHe data.

183 While early studies drew heavily on a He diffusion kinetic model derived from laboratory

184 experiments on the Durango fluorapatite ("Durango model", Farley, 2000), it is now

185 known that radiation damage strongly influences apatite He diffusivity (Shuster et al.,

186 2006). This effect is manifested as date-eU correlations in apatite suites that experienced

187 especially susceptible thermal histories (e.g., Flowers et al., 2007). The radiation damage

188 accumulation and annealing model (RDAAM) accounts for the evolution of apatite $\mathrm{He}$

189 retentivity during the addition and elimination of $\alpha$-damage (Flowers et al., 2009). A

190 similar model was proposed by Gautheron et al. (2009). Experiments suggest that fission

191 damage annealing is a reasonably good proxy for the annealing of damage that influences 
192 He diffusion (Shuster and Farley, 2009), so the RDAAM uses a fission track annealing

193 model to follow radiation damage elimination (Flowers et al., 2009; see also section 3.2).

194 Helium diffusivity will vary among apatites in a rock due to variations in

195 radiation damage and grain size. Similarly, diffusivity varies over the history of the

196 apatite crystal owing to accumulation and annealing of radiation damage. Thus for a rock

197 that has spent time in the region of partial He retention $\left(90-30^{\circ} \mathrm{C}\right)$, He dates may vary

198 from crystal to crystal well outside of an individual date's analytical precision. Provided

199 the date variability can be related to causative factors (grain size, eU, annealing

200 properties, crystal fragmentation), this variability enhances the thermochronometric value

201 of a suite of dates from the same rock (e.g., Brown et al., 2013; Flowers and Kelley,

202 2011). However, if date variability is uncorrelated with such factors, interpretation is

203 problematic and may lead to failure of inverse thermal history models to yield any

204 acceptable tT paths, or require the analyst to make subjective choices concerning how to

205 use over-dispersed data, whether by some kind of averaging or choosing which grains to

206 include and exclude. Thus great care must be exercised when modeling samples with

207 inexplicably large variability in AHe dates.

208

$209 \quad 3.2$ The apatite fission-track system

210 Unique among naturally occurring isotopes, ${ }^{238} \mathrm{U}$ undergoes spontaneous fission at

211 a geologically significant rate. The high energy of this decay is carried off as motion of a

212 pair of fission daughters whose passage through crystals is recorded in the form of a

213 damage track. Given a fission decay constant for ${ }^{238} \mathrm{U}$, the $\mathrm{U}$ concentration, and the

214 density of fission tracks (FTs), an accumulation time or date can be obtained. In the case 
215 of apatite, FTs can be revealed for microscopic examination and counting through acid

216 etching. Apatite FTs experience time and temperature-dependent annealing, so an AFT

217 date is, like a (U-Th)/He date, a reflection of the apatite's tT path. The AFT system is

218 especially sensitive to temperatures in the range $\sim 60-110^{\circ} \mathrm{C}$ (Gleadow and Duddy, 1981),

219 with possible resolution of still lower temperatures (Ketcham et al., 2009), and

220 fluorapatite is typically assigned a closure temperature of $\sim 100^{\circ} \mathrm{C}$.

221 An AFT date is obtained by counting the abundance of spontaneous fission tracks

222 revealed in an acid-etched polished surface, and comparing that abundance with a $\mathrm{U}$

223 concentration determined either by counting of ${ }^{235} \mathrm{U}$ fission tracks induced by neutron

224 activation, or by using LA-ICPMS. Due to historic and in some cases ongoing

225 uncertainties with a number of relevant quantities, including the fission decay constant,

226 reactor neutron fluence measurement, and track revelation and measurement efficiency

227 and bias, most labs calculate dates based on age standards using the zeta method

228 (Hurford, 1990; Donelick et al., 2005), although some groups endorse absolute age

229 determination (e.g., Enkelmann et al., 2005). The number of spontaneous tracks exposed

230 in a polished grain surface is typically small, leading to large statistical variations

231 between grains of the same age. "Pooled" AFT dates for a sample are obtained by simply

232 combining observations from multiple individual apatite grains. When the date dispersion

233 among a population of grains from a single sample exceeds that expected from

234 Poissonian statistics applied to the number of tracks counted, it is common to report the

235 geometric mean of the dates, called the central age (Galbraith and Laslett, 1993).

236 Fission-track length (FTL) data are obtained from confined horizontal tracks, in

237 which etchant has traveled into the grain via some pathway (typically a fission track or 
238 cleavage plane) and intersected and etched out an interior track with both ends enclosed

239 in the solid. Revelation of FTL's can be enhanced by bombarding the polished grain

240 surface prior to etching with ${ }^{252} \mathrm{Cf}$ fission fragments (Donelick and Miller, 1991) or heavy

241 ions (Jonckheere et al., 2007). Because apatite is anisotropic with respect to both etching

242 and annealing, the angle of each confined track to the crystallographic $\mathbf{c}$ axis is also

243 usually measured. FTL data may be normalized for anisotropy using $\mathbf{c}$-axis projection,

244 which converts each track to an estimated c-axis-parallel equivalent (Donelick et al.,

245 1999). Because they incorporate additional information, projected track lengths are

246 generally more precise indicators of thermal history than unprojected lengths (R. a.

247 Ketcham et al., 2007). FTL data is also prone to biases and variation among analysts, and

248 it has recently been proposed that calibration against length standards and $\mathbf{c}$-axis

249 projection should be used to improve inter-laboratory reproducibility (Ketcham et al., $250 \quad 2015)$

251 The annealing process involves progressive shortening of the FT from an initial

252 length of $16-18 \mu \mathrm{m}$ until it ultimately disappears. Each track within an apatite has

253 experienced the temperature history and any associated track shortening from the time of

254 the track's formation until the present. Thus, the FTL distribution provides additional

255 information on the sample's tT path. The complementarity between an AFT date and its

256 associated FTL distribution is analogous to that of an AHe date and its ${ }^{4} \mathrm{He} /{ }^{3} \mathrm{He}$ spectrum.

257 FTL distributions are commonly reported either as a table of measured lengths, or as a

258 mean track length and standard deviation. For tT modeling the complete distribution,

259 rather than a statistical abstraction, is essential. 
261 annealing, which in turn provides a foundation for kinetic models used to constrain a tT

262 path from AFT dates and FTL distributions. In addition to primary control by

263 temperature, the annealing rate and thus closure temperature of AFTs is affected by

264 chemistry, in particular the relative abundance of $\mathrm{Cl}$ (and possibly $\mathrm{OH}$ ) in the anion site,

265 as well as some cation substitutions (e.g., Carlson et al., 1999; Green et al., 1986). Thus

266 reliable interpretation of AFT data requires information about apatite annealing kinetics.

267 Annealing kinetics can be estimated based on a single compositional variable (i.e. $\mathrm{Cl}$

268 content), a multi-compositional approach ( $r_{m r}$; Ketcham et al., 1999), or solubility,

269 which reflects chemistry and is conveniently measured as the diameter of etch figures

270 parallel to the $\mathbf{c}$ axis ( $\mathrm{D}_{\text {par; }}$ B Burtner et al., 1994).

271 Ideally the kinetic parameter should be measured on every apatite grain used in

272 age and length measurements, and, analogously to date-eU correlations for AHe, kinetic

273 effects can be inspected for by plotting single-grain dates and track lengths against the

274 kinetic parameter. If correlations are found, it is often possible to group measurements

275 into statistically coherent populations with distinct annealing properties that can be

276 modeled in tandem. Although this step is frequently omitted during interpretation and

277 modeling, doing so is hazardous, as mixed populations of ages and lengths may lead to

278 nonsensical results if interpreted with the assumption that they are kinetically

279 homogeneous. Although several apatite fission-track annealing models are available for

280 interpreting FTLs and AFT dates (e.g., Crowley et al., 1991; Laslett et al., 1987), only the

281 more recent ones incorporate compositional and track-angle information (Ketcham et al.,

282 1999; Ketcham et al., 2007b). 


\section{4. Thermal history modeling and its documentation}

\section{4.1. Model inputs, outputs, and interpretation}

286 Although AHe and AFT results are reported as dates, these quantities typically do

287 not indicate the date of a geologic event or even cooling through the closure temperature.

288 Instead they are single-valued quantities that capture the apatite's integrated thermal

289 history since the onset of He retention and/or radiation damage accumulation. Inversion

290 models (e.g., Ketcham, 2005) are used to constrain this thermal history, and so are at the

291 core of making geologic interpretations from thermochronologic measurements. The

292 inversion models take kinetic models that describe how the AHe and AFT systems

293 respond as a function of temperature and time, and yield tT paths consistent with

294 thermochronometric observations and a priori geologic constraints.

295 A diversity of tT paths can yield the same AHe or AFT date, so a unique path 296 generally cannot be determined. Combining multiple approaches $\left(\mathrm{AHe}, \mathrm{AFT},{ }^{4} \mathrm{He} /{ }^{3} \mathrm{He}\right.$,

297 FTL distributions) on a single sample can reduce this non-uniqueness. Similarly, samples

298 strategically drawn from the landscape or down a borehole can restrict feasible tT paths.

299 For example, elevation transects are commonly employed because the paths must be

300 internally consistent across the sample suite (e.g., Gallagher, 2012). Geologic

301 considerations, such as igneous crystallization ages, the age of a faulted volcanic unit, or

302 the age of an unconformity, can also eliminate possible paths. Geologic constraints can

303 strongly bias inversion model output, so these must be defined and justified with

304 appropriate rigor. 
Even with the numerous constraints provided by multiple systems and samples,

306 inversion model outputs are typically a swath of acceptable tT paths. The question of how

307 one defines acceptability given diverse data types and sometimes poorly characterized

308 uncertainties is a complex topic that we do not address here. Several contributions discuss

309 the rationale for the approaches employed by HeFTy and QTQt, the two most widely

310 used inverse modeling programs for thermochronologic data (Gallagher, 2012, 1995;

311 Ketcham, 2005; Vermeesch and Tian, 2014).

312 A key point of this paper is that in addition to the target dates, ${ }^{4} \mathrm{He} /{ }^{3} \mathrm{He}$ spectra,

313 and FTL distributions, these models require specification of a large number of additional

314 quantities. These include, for example, the ancillary information required for kinetic

315 modeling (Sections 3.1 and 3.2, Figure 1) as well as specification of initial and final

316 temperature conditions, the character of the allowed tT paths, the statistical fitting

317 thresholds applied, and any imposed geologic constraints. Without documentation of all

318 of this input information, the modeling results cannot readily be reproduced.

319 Equally important is the clear, complete, and accurate representation of the

320 thermal history model outputs. Within the swath of acceptable fits, there is no statistical

321 justification to prefer the "best fit" path over the others. Summary paths, such as a

322 weighted mean (Ketcham 2005) or Bayesian "expected model" (Gallagher 2012), can

323 sometimes be helpful when comparing multiple model results, but their use in this

324 manner can also be perilous if it's not made clear that they are simplifications of a much

325 wider range of acceptable solutions. Some characterization of the full suite of statistically

326 valid tT paths should be displayed on the tT result plot whenever possible, and must be

327 made easily available elsewhere when not, because its omission makes it impossible to 
328 evaluate the actual restrictiveness of the model output. The imposed tT constraints should

329 also be shown, because without them one cannot assess the extent to which these defined

330 constraints or the thermochronologic data determined the model results.

331 When interpreting and discussing the model outputs, it is important to distinguish

332 between results that require, exclude, or are consistent with a particular interpretation (see

333 example in section 5.3). Geologic conclusions based on these results then entail

334 additional assumptions about geotherms, surface temperatures, and other factors.

336 4.2. The thermal history model input table

337 Level 1 of the interpretational framework (Fig. 1) encompasses the totality of the

338 building blocks from which the Level 2 results - the thermal history model outputs - are

339 derived. We suggest that use of a model input table with which to clearly define,

340 rigorously explain, and, if necessary, provide references for, each and every one of the

341 Level 1 inputs to thermal history models would help clarify how thermochronologic

342 conclusions are derived in individual studies. Table 1 is an example, which subdivides

343 the input parameters into 3 types: thermochronologic data, additional geologic

344 information, and system- and model-specific parameters.

345 The thermochronologic data include a list of all thermochronologic information

346 constraining a given model, as well as where the data needed to reproduce the model

347 were published if not reported in the same paper. This section additionally notes the

348 uncertainties applied, catalogues any ancillary data used or assumed in the thermal

349 history simulations (e.g., eU zonation or weight \% Cl), and explains how the data were

350 treated - for example, whether and how data from multiple analyses or rocks were 
351 combined. The second type of model input includes all other constraints imposed on the

352 tT paths, which are typically derived from geologic information. Not only should the

353 imposed tT constraint be listed, but the geologic rationale for it articulated, and the

354 relevant reference provided. Model-specific parameters compose the final suite of Level

3551 building blocks. We include here the kinetic models used, the statistical fitting criteria

356 applied for defining the tT paths allowed by the data, the modeling code employed, and

357 details such as the number of thermal histories evaluated.

358 The structure of the model input table underscores that by linking together

359 different Level 1 elements, different Level 2 tT outputs may be obtained. For example,

360 as further analyses are undertaken, the number of available chronometric elements may

361 increase. Or a new or different diffusion kinetic model may replace the one originally

362 chosen. Similarly, by excluding or modifying a specific Level 1 element, it becomes

363 possible to assess which element drives specific aspects of the Level 2 results. We next

364 illustrate the value of such a model input table using as an example a thermochronologic

365 dataset from the Grand Canyon.

366

367 5. An Illustration of the Model Input Table using the Westernmost Grand Canyon

368 The age of the Grand Canyon has long puzzled geologists. The prevailing model

369 has held that the entire canyon was carved after $6 \mathrm{Ma}$ (e.g., Karlstrom et al., 2008), but

370 recent thermochronologic datasets have reinvigorated discussion about the canyon's

371 antiquity. AHe and ${ }^{4} \mathrm{He} /{ }^{3} \mathrm{He}$ data were used to argue for a multiphase history in which the

372 modern gorge of the western (but not the eastern) canyon was partially excavated by $\sim 70$

373 Ma (Flowers and Farley, 2012; Wernicke, 2011). Several ensuing studies used additional 
374 thermochronologic data to similarly conclude that the canyon's history was more

375 complex than simple post-6 Ma incision (Lee et al., 2013) with one segment as old as 65

$376 \mathrm{Ma}$ (Karlstrom et al., 2014). Thus, recent debate has shifted to focus on which reaches of

377 the Grand Canyon are old, and when and how different paleocanyon segments became

378 linked. A point of disagreement is whether the westernmost Grand Canyon (WGC; Fig.

$3792 \mathrm{~A}, 2 \mathrm{~B}$ ) is ancient (partially carved by $70 \mathrm{Ma}$; Flowers and Farley, 2012; Wernicke,

380 2011) or young (incised entirely after $6 \mathrm{Ma}$; Karlstrom et al., 2014). The dataset for this

381 canyon segment includes AHe, ${ }^{4} \mathrm{He} /{ }^{3} \mathrm{He}, \mathrm{AFT}$, and FTL data for multiple samples. Our

382 objective here is not to address the canyon's age, but rather to show how a rigorous

383 reporting protocol, as well as complete model output representation, can facilitate

384 understanding of thermochronologically-derived conclusions.

\subsection{Thermochronologic data}

The thermochronologic data currently available for the WGC are shown in Figure 2B. All samples are Proterozoic basement from an $\sim 56 \mathrm{~km}$ stretch of the canyon bottom.

389 The data include AHe results for seven samples, four of which have U-Th zonation data

390 (Flowers and Farley, 2012; Flowers et al., 2008; Lee et al., 2013). Fourteen apatite

$391{ }^{4} \mathrm{He} /{ }^{3} \mathrm{He}$ spectra are available for two of them (Flowers and Farley, 2012). AFT dates are

392 reported for 4 samples (Kelley et al., 2001; Lee et al., 2013). Three of these have FTL

393 information and 3 have coexisting AHe data.

394 The data are plotted versus River Mile in Figures 2C, 2E, and 2F, measured by 395 convention from Lee's Ferry (RM 0). Six of the samples with AHe data include 29 single-

396 grain analyses generated independently in two labs, and yield mean sample dates from 
70-89 Ma and within-sample reproducibilities of 4-13\% (red symbols, Fig. 2C). This age

398 clustering and level of reproducibility supports the reliability of the dataset. In contrast, a

399 seventh rock (01GC86) with $43 \%$ dispersion $(1 \sigma)$ for three AHe dates, coupled with its

400 much younger mean date of $50 \mathrm{Ma}$, suggest a problematic sample (blue symbol, Fig. 2C).

401 As noted in section 3.1, AHe samples like this one with extreme date scatter for which no

402 kinetic control has been identified are generally inappropriate for inversion modeling.

403 Of the available ${ }^{4} \mathrm{He} /{ }^{3} \mathrm{He}$ spectra, only the CP06-69 data are adequate for

404 modeling (Fig. 2D). The three replicate spectra for this sample are similar, although the

405 third grain (not shown in Fig. 2D) included an anomalous final step in the spectrum. This

406 sample's apatites have similar and fairly muted U-Th zoning patterns. In contrast, the

407 eleven ${ }^{4} \mathrm{He} /{ }^{3} \mathrm{He}$ spectra from sample GC863 are highly variable, likely a consequence of

408 the observed extreme and variable U-Th zonation. As discussed in Section 3.1, such

409 apatites will have ${ }^{4} \mathrm{He} /{ }^{3} \mathrm{He}$ spectra dominated by the comparatively uncertain parent

410 nuclide distribution rather than by diffusion, and so are inappropriate for $\mathrm{tT}$ modeling.

411 The available AFT dates range from $75 \pm 5 \mathrm{Ma}$ to $63 \pm 4 \mathrm{Ma}$, reported as the central

412 age and $1 \sigma$ S.E. of the pooled dates (Fig. 2E; Kelley et al., 2001; Lee et al., 2013). FTL

413 distributions of the three samples are distinct, varying from $14.0 \pm 0.4$ um to $12.1 \pm 0.4 \mathrm{um}$

414 (mean and $1 \sigma$ S.E.). Individual grain dates, FTLs, and kinetic parameters were not

415 published, precluding others from modeling these data and rigorously evaluating the

416 conclusions derived from them. 
419 To illuminate how discrepant conclusions were reached about the age (70 Ma vs.

$420<6 \mathrm{Ma})$ of the WGC from the above dataset, we assembled the model input tables for the

421 relevant thermal history simulations using the information provided in Flowers and

422 Farley $(2012,2013)$ and Karlstrom et al. (2014). All simulations used the HeFTy

423 software program. For simplicity we label the simulations from \#1-6 in the tables,

424 figures, and text.

425 Table 2 is the model input table for the 3 key simulations of Flowers and Farley

$426(2012,2013)$ from which their ancient WGC interpretation was derived. Their approach

427 was to simultaneously satisfy all Level 1 thermochronologic data from the WGC, which

428 assumes that this suite of canyon bottom samples experienced the same thermal history.

429 Simulation \#1 included duplicate ${ }^{4} \mathrm{He} /{ }^{3} \mathrm{He}$ spectra for CP06-69, as well as all 4 then

430 available AHe samples and their U-Th zonation data (Table 2). It was impossible to

431 include the only then available WGC AFT data (sample 98GC38) in this inverse model,

432 because the individual grain dates and FTLs were unpublished (Kelley et al., 2001; see

433 section 5.1). However, the Cretaceous central age and long FTLs reported for this sample

434 indicated complete annealing of FTs at peak temperature, providing a zero radiation

435 damage, zero He date initial condition for modeling. Consequently, the inversion model

436 was initiated at $100-80 \mathrm{Ma}$ at temperatures $\geq 110{ }^{\circ} \mathrm{C}$ to honor this AFT constraint. The

437 only other tT constraint imposed was the requirement to reach modern surface

438 temperatures of $20-25^{\circ} \mathrm{C}$ by present day. Two other simulation variants included AHe

439 data for a single sample only ( $\operatorname{sim} \# 2)$, or incorporated the ${ }^{4} \mathrm{He} /{ }^{3} \mathrm{He}$ spectrum for a third

440 apatite (spectrum b from CP06-69 with an anomalous final step; sim \#3; Flowers and 
441 Farley, 2013). These latter simulations were considered consistency checks because they

442 did not seek to honor all available data simultaneously.

443 Lee et al. (2013) subsequently reported new AHe and AFT data for 3 WGC

444 samples, but performed a tT simulation for only one of them. Karlstrom et al. (2014)

445 carried out 3 thermal history models, one for each of these new samples. Unfortunately,

446 the AFT single grain dates and FTLs necessary for others to reproduce these simulation

447 results and generate additional models remain unpublished. The Karlstrom et al. (2014)

448 models, which we here call simulations 4, 5, and 6, differ from those of Flowers and

449 Farley $(2012,2013)$ in modeling different samples, using AFT dates and FTLs as Level 1

450 observations, not using ${ }^{4} \mathrm{He} /{ }^{3} \mathrm{He}$ data, and using different $\mathrm{tT}$ constraints that limit peak

451 temperatures to $\leq 110{ }^{\circ} \mathrm{C}$. Importantly, Karlstrom et al. (2014) treat each sample

452 separately rather than simultaneously satisfying all data, therefore relaxing the

453 requirement that all WGC samples have the same thermal history. Simulation \#4 models

454 the AHe and AFT dates for sample 01GC89 (no FTL data are available). Simulation \#5

455 simulates the AHe, AFT, and FTL data for sample 01GC87. Simulation \#6 uses the

456 problematic AHe data from sample 01GC86 (Fig. 2C, blue symbols).

$458 \quad$ 5.3. Model outputs and their interpretation (Levels 2 and 3)

459 The distinct conclusions regarding when the WGC was initially carved arise from

460 the differing tT model results in Figure 3. Results for simulations \#1-3 from Flowers and

461 Farley $(2012,2013)$ are displayed as individual tT paths (Fig. 3A-C). The key result is

462 that all thermal histories require cooling to $<30^{\circ} \mathrm{C}$ by $70 \mathrm{Ma}$. This result is supported by

463 both simulation \#1 that honored multiple observations simultaneously (Fig. 3A; Flowers 
464 and Farley, 2012), as well as the consistency checks provided by simulating AHe and

$465{ }^{4} \mathrm{He} /{ }^{3} \mathrm{He}$ data for a single sample only (sim \#2, Fig. 3B) and by including the ${ }^{4} \mathrm{He} /{ }^{3} \mathrm{He}$

466 spectrum for a third apatite (sim \#3, Fig. 3C; Flowers and Farley, 2013). This outcome is

467 consistent with the previously published simulation result for what was then the only

468 available westernmost canyon AFT data (sample 98GC38), which allowed for (but did

469 not require) cooling to $30^{\circ} \mathrm{C}$ by ca. $65 \mathrm{Ma}$ (Fig. 3D, from Kelley et al., 2001, tT path

470 output shown as fields). Based on this internal consistency, Flowers and Farley (2012,

471 2013) concluded that rocks along the bottom of the WGC segment had cooled to $<30{ }^{\circ} \mathrm{C}$

472 by $70 \mathrm{Ma}$. They then argued that $20-25^{\circ} \mathrm{C} / \mathrm{km}$ and $20-25^{\circ} \mathrm{C}$ are appropriate geotherm and

473 surface temperature estimates, respectively, and assuming these values concluded that the

$474 \sim 1000 \mathrm{~m}$ deep modern gorge of the WGC was partially carved by $70 \mathrm{Ma}$. They also

475 contended that the predictions of a thermal history associated with entirely post- $6 \mathrm{Ma}$

476 incision are inconsistent with the $\mathrm{AHe}$ and ${ }^{4} \mathrm{He} /{ }^{3} \mathrm{He}$ data (Flowers and Farley, 2012).

477 The key figure from Karlstrom et al. (2014) representing their model outputs is

478 shown in Figure 3E. This plot depicts seven different tT model results, including those

479 for simulations \#4-6 discussed in the previous section, results for two additional samples

480 not from the WGC, the AFT model result of Kelley et al. (2001), and the swath of results

481 from simulation \#3 of Flowers and Farley (2013). For most of these models Karlstrom et

482 al. (2014) chose to depict only a single path (unspecified, but most likely the weighted

483 mean of acceptable paths), rather than the full suite of statistically valid results. They also

484 do not show the tT constraints imposed on the models here. Karlstrom et al. (2014) used

485 this figure to support their conclusion of variable thermal histories along the WGC and

486 young $(<6 \mathrm{Ma})$ canyon incision, because at face value Figure 3D suggests rather extreme 
487 variations in tT paths, with many samples seemingly supporting temperatures $>30{ }^{\circ} \mathrm{C}$

488 until well after 70 Ma. However, by referring to the model input table (Table 3), as well

489 as to the full output plots for several models, we can assess why this variability exists and

490 whether it is required. Two of the model results depicted on Figure 3E (dark blue curves)

491 are for two samples located $\sim 60 \mathrm{~km}$ to the northeast of the WGC, and therefore should

492 not be included on a model output plot entitled "westernmost Grand Canyon".

493 Consideration of the complete swaths of results for simulation \#4 (Fig. 3F, Karlstrom et

494 al. 2014 supplement) and the AFT simulation of Kelley et al. (2001) (Fig. 3D) reveals

495 that some results are compatible with those of simulations \#1-3 in permitting cold

$496\left(<30^{\circ} \mathrm{C}\right)$ temperatures by $65 \mathrm{Ma}$. Karlstrom et al. (2014)'s depiction of only a single path

497 in Figure 3E (red curves) for these model results could be taken to imply that the data

498 require the single tT path shown, which would lead to the incorrect conclusion that the

499 data require temperatures warmer than $30{ }^{\circ} \mathrm{C}$ long after $70 \mathrm{Ma}$, when they do not (see

500 section 4.1). Finally, one of these simulations fit a sample with He dates that are

501 analytically suspect and should not be used for tT interpretation (sim \#6, see Section 5.1,

502 light blue curve in Fig. 3E).

503 Ultimately, after considering these factors, only one simulation result (sim \#5 in

504 Fig. 3E) is inconsistent with early cooling to cold temperatures like that required by

505 simulations \#1-3 of Flowers and Farley $(2012,2013)$. This model's requirement for

506 elevated temperatures until the end of the Miocene stems from the mean FTL of $12.1 \mu \mathrm{m}$,

507 but many relevant details are unavailable, including the measurement and calibration

508 procedures.

509 
511 The Grand Canyon example shows how complex and confusing it can be to

512 understand the origin of geologic interpretations when the data necessary for modeling

513 are not published, and when model outputs are incompletely represented. From initial

514 inspection of the contributions by Flowers and Farley (2012) and Karlstrom et al. (2014)

515 it appears that their WGC thermochronologic datasets require dramatically divergent

516 conclusions about this canyon segment's age ( 70 Ma vs. $<6 \mathrm{Ma})$. However, closer

517 evaluation indicates that when one includes only samples actually from the WGC, if the

518 full model outputs are considered, and if simulations using questionable data are rejected,

519 all but one model result displayed by Karlstrom et al. (2014) in Figure 3E are compatible

520 with those of Flowers and Farley $(2012$, 2013) (sims \#1-3, Fig. 3A-C) and thus also are

521 consistent with the ancient canyon interpretation. Additional work is needed to determine

522 if the discrepant model result yielded by simulation \#5 is sample specific, such as due to

523 a localized reheating event by WGC Quaternary volcanism, or if it reflects a broader

524 intercalibration issue with the AHe and AFT systems, suggesting that some aspect of the

525 mutually agreed upon He diffusion kinetic (Fox and Shuster, 2014) or FT annealing

526 models currently used by the thermochronology communities must be modified or

527 augmented to reconcile the WGC datasets.

529 6. Concluding Remarks

530 Complete publication of all data necessary for thermal history modeling, together

531 with clear documentation of model inputs and outputs, is necessary to enhance

532 understanding of thermochronologic datasets and refinement of the methods being 
533 applied. The proposed model input reporting table provides a mechanism to assist the

534 rapidly growing thermochronologic user base in key considerations of inverse tT

535 modeling. In particular, it provides an organizational framework that helps ensure that all

536 relevant information is reported, rather than relying on a loose collection of tables and

537 prose, and that the modeler will give each aspect of model input the care and attention a

538 scientific product requires. Additionally, for complex datasets in which divergent

539 conclusions are reached by different studies, transparency in the choice of model inputs

540 and outcomes would facilitate evaluation of how various assumptions influence the

541 interpretations, identify where discrepancies between datasets truly do or do not exist,

542 and thus aid in determining the extent to which intra- and inter-method calibration efforts

543 are needed. The Grand Canyon example shows how the origin of thermochronologic

544 interpretations can be clarified using this approach.

545 We hope that the suggested reporting table template will stimulate additional

546 community discussion about modeling philosophies and reporting formats. In the near-

547 term, including the reporting tables and HeFTy or QTQt model files in on-line

548 supplements would assist with attainment of the goals outlined here. Over the longer-

549 term, we envision that if clear, rigorous, and community-agreed upon definitions of Level

5501 elements (i.e., for as many constituents of the model input file as practical) were

551 established, then a community database of model input files could add value in much the

552 same way as does a database of sample dates. If one or more modeling tools were capable

553 of ingesting such files and generating the swath of acceptable tT paths, this would readily

554 allow a user to reproduce a published Level 2 product. Moreover, if the Level 2 product

555 had an agreed upon format that includes the tT swath and all ancillary data used in its 
generation (i.e., an output version of the model input file that is tagged to the swath), then

557 a user could simply locate the Level 2 product from a publication (archived

558 electronically), and either work directly with the reported swath of tT paths (i.e., move on

559 to Level 3), or explore how the selection of Level 1 elements influences the Level 2

560 product. Such a database of model input and output files to archive and clarify the path of

561 argument used to reach published interpretations would promote the transparency, value,

562 and understanding of thermochronologic data in future investigations.

564 Acknowledgements: Supported by NSF EAR-1144500 and EAR-1126991. We thank

565 Todd Ehlers and Lon Abbott for insightful comments on the manuscript.

567 References Cited

Ault, A.K., Flowers, R.M., 2012. Is apatite U-Th zonation information necessary for accurate interpretation of apatite (U-Th)/He thermochronometry data? Geochim. Cosmochim. Acta 79, 60-78. doi:10.1016/j.gca.2011.11.037

Brown, R.W., Beucher, R., Roper, S., Persano, C., Stuart, F., Fitzgerald, P., 2013. Natural age dispersion arising from the analysis of broken crystals. Part I: Theoretical basis and implications for the apatite (U-Th)/He thermochronometer. Geochim. Cosmochim. Acta 122, 478-497. doi:10.1016/j.gca.2013.05.041

Burtner, R.L., Nigrini, A., Donelick, R.A., 1994. Thermochronology of lower Cretaceous source rocks in the Idaho-Wyoming thrust belt. Am. Assoc. Pet. Geol. Bull. 78, 1613-1638.

Carlson, W.D., Donelick, R.A., Ketcham, R.A., 1999. Variability of apatite fission-track annealing kinetics :I. Experimental results 84, 1213-1223.

Crowley, K.D., Cameron, M., Schaefer, R.L., 1991. Experimental studies of annealing of etched fission tracks in fluorapatite. Geochim. Cosmochim. Acta 55, 1449-1465.

Dodson, M.H., 1973. Closure temperatures in cooling geological and petrological systems. Contrib. to Mineral. Petrol. 40, 259-274. 
Donelick, R.A., Miller, D.S., 1991. Enhanced TINT fission track densities in low spontaneous track density apatites using 252Cf-derived fission fragment tracks: A model and experimental observations. Nucl. Tracks Radiat. Meas. 18, 301-307.

Donelick, R.A., O’Sullivan, P.B., Ketcham, R.A., 2005. Apatite fission-track analysis. Rev. Mineral. Geochemistry 58, 49-94.

Enkelmann, E., Jonckheere, R., Wauschkuhn, B., 2005. Independent fission-track ages $(\varphi$-ages) of proposed and accepted apatite age standards and a comparison of $\varphi$-, Z-, $\zeta-$, and $\zeta 0$ - ages: Implications for method calibration. Chem. Geol. 222, 232-248.

Farley, K.A., 2000. Helium diffusion from apatite: General behavior as illustrated by Durango fluorapatite. J. Geophys. Res. 105, 2903-2914.

Farley, K.A., Shuster, D.L., Ketcham, R.A., 2011. U and Th zonation in apatite observed by laser ablation ICPMS, and implications for the (U-Th)/He system. Geochim. Cosmochim. Acta 75, 4515-4530. doi:10.1016/j.gca.2011.05.020

Farley, K.A., Shuster, D.L., Watson, E.B., Wanser, K.H., Balco, G., 2010. Numerical investigations of apatite $4 \mathrm{He} / 3 \mathrm{He}$ thermochronometry. Geochemistry, Geophys. Geosystems 11, 1-18. doi:10.1029/2010GC003243

Farley, K.A., Wolf, R.A., Silver, L.T., Wolf, L.T., 1996. The effects of long alphastopping distances on (U-Th)/He ages. Geochim. Cosmochim. Acta 60, 4223-4229.

Flowers, R.M., Farley, K.A., 2012. Apatite 4He/3He and (U-Th)/He evidence for an ancient Grand Canyon. Science 338, 1616-9. doi:10.1126/science.1229390

Flowers, R.M., Farley, K.A., 2013. Response to Comments on "Apatite $4 \mathrm{He} / 3 \mathrm{He}$ and (UTh)/He Evidence for an Ancient Grand Canyon." Science (80-. ). 340, 143-143. doi: $10.1126 /$ science. 1234203

Flowers, R.M., Kelley, S.A., 2011. Interpreting data dispersion and "inverted" dates in apatite (U-Th)/He and fission-track datasets: An example from the US midcontinent. Geochim. Cosmochim. Acta 75, 5169-5186. doi:10.1016/j.gca.2011.06.016

Flowers, R.M., Ketcham, R.A., Shuster, D.L., Farley, K.A., 2009. Apatite (U-Th)/He thermochronometry using a radiation damage accumulation and annealing model. Geochim. Cosmochim. Acta 73, 2347-2365. doi:10.1016/j.gca.2009.01.015

Flowers, R.M., Shuster, D.L., Wernicke, B.P., Farley, K.A., 2007. Radiation damage control on apatite (U-Th)/He dates from the Grand Canyon region, Colorado Plateau. Geology 35, 447-450. doi:10.1130/G23471A.1 
Flowers, R.M., Wernicke, B.P., Farley, K.A., 2008. Unroofing, incision and uplift history 618 of the southwestern Colorado Plateau from (U-Th)/He apatite thermochronometry.

$619 \quad$ Geol. Soc. Am. Bull. 120, 571-587. doi:10.1130/B26231.1

620 Fox, M., Shuster, D.L., 2014. The influence of burial heating on the (U-Th)/He system in apatite: Grand Canyon case study. Earth Planet. Sci. Lett. 397, 174-183. doi:10.1016/j.epsl.2014.04.041

623 Gallagher, K., 1995. Evolving temperature histories from apatite fission-track data. Earth

648 Karlstrom, K.E., Lee, J.P., Kelley, S.A., Crow, R.S., Crossey, L.J., Young, R.A., Lazear,

Gallagher, K., 2012. Transdimensional inverse thermal history modeling for quantitative thermochronology. J. Geophys. Res. 117, B02408. doi:10.1029/2011JB008825

Gautheron, C., Tassan-Got, L., Barbarand, J., Pagel, M., 2009. Effect of alpha-damage annealing on apatite (U-Th)/He thermochronology. Chem. Geol. 266, 157-170.

Gleadow, A.J.W., Duddy, I.R., 1981. A natural long-term annealing experiment for apatite. Nucl. Tracks Radiat. Meas. 5, 169-174.

Green, P.F., Duddy, I.R., Gleadow, A.J.W., Tingate, P.R., Laslett, G.M., 1986. Thermal annealing of fission tracks in apatite 1. A qualitative description. Chem. Geol. 59, 237-253.

Gurnis, M., Flesch, L., Okaya, D., Peters, S., Walker, D., Ahern, T., Bolder, F., Arrowsmith, J.R., 2012. A preliminary strategic plan for EarthScope cyberinfrastructure. White Pap.

Hourigan, J.K., Reiners, P.W., Brandon, M.T., 2005. U-Th zonation-dependent alphaejection in (U-Th)/He chronometry. Geochim. Cosmochim. Acta 69, 3349=3365.

Johnstone, S., Hourigan, J., Gallagher, C., 2013. LA-ICP-MS depth profile analysis of apatite: Protocol and implications for (U-Th)/He thermochronometry. Geochim. Cosmochim. Acta 109, 143-161. doi:10.1016/j.gca.2013.01.004

Jonckheere, R., Enkelmann, E., Min, M., Trautmann, C., Ratschbacher, L., 2007. Confined fission tracks in ion-irradiated and step-etched prismatic sections of Durango apatite. Chem. Geol. 242, 202-217.

Karlstrom, K.E., Crow, R., Crossey, L.J., Coblentz, D., Van Wijk, J.W., 2008. Model for tectonically driven incision of the younger than $6 \mathrm{Ma}$ Grand Canyon. Geology 36, 835. doi:10.1130/G25032A.1 G., Beard, L.S., Ricketts, J.W., Fox, M., Shuster, D.L., 2014. Formation of the 
Grand Canyon 5 to 6 million years ago through integration of older palaeocanyons. doi:10.1038/NGEO2065

652

653

654

655

656

657

658

659

660

661

662

663

664

665

666

667

668

669

670

671

672

673

674

675

676

677

678

679

680

681

682

Kelley, S.A., Chapin, C.E., Karlstrom, K.E., 2001. Laramide cooling histories of Grand Canyon, Arizona and the Front Range, Colorado, determined from apatite fissiontrack thermochronology, in: Young, R.A., Spamer, E.E. (Eds.), Colorado River Origin and Evolution. Grand Canyon Association, pp. 37-46.

Ketcham, R. a., Carter, A., Donelick, R. a., Barbarand, J., Hurford, A.J., 2007. Improved measurement of fission-track annealing in apatite using c-axis projection. Am. Mineral. 92, 789-798. doi:10.2138/am.2007.2280

Ketcham, R.A., 2005. Forward and inverse modeling of low temperature thermochronometry data, in: Reiners, P.W., Ehlers, T.A. (Eds.), Thermochronology. Reviews in Mineralogy and Geochemistry, pp. 275-314.

Ketcham, R.A., Carter, A., Hurford, A.J., 2015. Inter-laboratory comparison of fission track confined length and etch figure measurements in apatite 100, 1452-1468.

Ketcham, R.A., Carter, A.C., Donelick, R.A., Barbarand, J., Hurford, A.J., 2007. Improved modeling of fission-track annealing in apatite. Am. Mineral. 92, 799-810.

Ketcham, R.A., Donelick, R.A., Carlson, Wi.D., 1999. Variability of apatite fission-track annealing kinetics : III . Extrapolation to geological time scales 84, 1235-1255.

Ketcham, R.A., Gautheron, C., Tassan-Got, L., 2011. Accounting for long alpha-particle stopping distances in (U-Th-Sm)/He geochronology: Refinement of the baseline case. Geochim. Cosmochim. Acta 75, 7779-7791. doi:10.1016/j.gca.2011.10.011

Laslett, G.M., Green, P.F., Duddy, I.R., Gleadow, A.J.W., 1987. Thermal annealing of fission tracks in apatite 2. A quantitative analysis. Chem. Geol. 65, 1-13.

Lee, J.P., Stockli, D.F., Kelley, S.A., Pederson, J.L., Karlstrom, K.E., Ehlers, T.A., 2013. New thermochronometric constraints on the Tertiary landscape evolution of the central and eastern Grand Canyon, Arizona 216-228. doi:10.1130/GES00842.1

Murray, K.E., Orme, D.A., Reiners, P.W., 2014. Effects of U-Th-rich grain boundary phases on apatite helium ages. Chem. Geol. 390, 135-151. doi:10.1016/j.chemgeo.2014.09.023

Reiners, P.W., Ehlers, T.A., 2005. Low-temperature thermochronology: Techniques, interpretations, and applications. Rev. Mineral. Geochemistry.

Shuster, D.L., Farley, K.A., 2003. 4He/3He thermochronometry. Earth Planet. Sci. Lett. $217,1-27$. 
Shuster, D.L., Farley, K.A., 2005. 4He/3He thermochronometry: theory, practice and potential complicatoins. Rev. Mineral. Geochemistry Low-Temperature Thermochronology Tech. Interpret. Appl. (ed. P. Reiners T. Ehlers) 58, 181-203.

Shuster, D.L., Farley, K.A., 2009. The influence of artificial radiation damage and thermal annealing on helium diffusion kinetics in apatite. Geochim. Cosmochim. Acta 73, 183-196.

Shuster, D.L., Flowers, R.M., Farley, K.A., 2006. The influence of natural radiation damage on helium diffusion kinetics in apatite. Earth Planet. Sci. Lett. 249, 148161. doi:10.1016/j.epsl.2006.07.028

Spiegel, C., Kohn, B., Belton, D., Berner, Z., Gleadow, A., 2009. Apatite (U-Th-Sm)/He thermochronology of rapidly cooled samples: The effect of He implantation. Earth Planet. Sci. Lett. 285, 105-114. doi:10.1016/j.epsl.2009.05.045

Vermeesch, P., Tian, Y., 2014. Thermal history modelling: HeFTy vs. QTQt. EarthScience Rev. 139, 279-290. doi:10.1016/j.earscirev.2014.09.010

Wernicke, B., 2011. The California River and its role in carving Grand Canyon. Geol. Soc. Am. Bull. 123, 1288-1316. doi:10.1130/B30274.1

\section{Figure Captions}

Figure 1. Interpretational framework showing the path from low level thermochronologic results and geologic observations to high level and potentially complex geologic interpretations.

Figure 2. (A) Shaded relief map for the Grand Canyon region with the Colorado River in blue. WGC segment marked by blue dots. Black square marks location of (B). (B)

Shaded relief map for the WGC with sample locations. Mean AHe dates reported with $1 \sigma$ standard deviation and number of analyses. AFT dates reported as central age and $1 \sigma$ standard error. TL denotes samples with FTL data. Sample with AHe date in gray has overdispersed data. White rectangle marks WGC segment. River miles marked as RM. 
711 (C) AHe date versus Grand Canyon river mile. Red symbols show the mean dates and

$7121 \sigma$ uncertainties for the samples with 4-13\% internal dispersion. The blue symbol marks

713 the anomalous sample with excess random scatter $(43 \% 1 \sigma)$. Light gray circles denote the

714 individual grain analyses for each sample. (D) Normalized ${ }^{4} \mathrm{He} /{ }^{3} \mathrm{He}$ step age plots for two

715 apatites from CP06-69. (E) AFT date versus river mile, reported as the central age and $1 \sigma$

716 standard error. (F) AFT mean track length versus river mile. Uncertainties are the

717 reported $1 \sigma$ standard error.

718

719 Figure 3. Outputs of the WGC models discussed in text. (A)-(C) Simulation \#1-3 results

720 for $\mathrm{AHe}$ and ${ }^{4} \mathrm{He} /{ }^{3} \mathrm{He}$ data depicted as individual tT paths, from Flowers and Farley

721 (2012, 2013). (D) Simulation results for sample 98GC38 AFT data with the complete

722 suite of output paths shown as fields, from Kelley et al. (2001). (E) Karlstrom et al.

723 (2014) depiction of their simulation results, in which they show the simulation \#3 results

724 of Flowers and Farley (2013) in the background. The full suite of viable tT paths are not

725 shown for 5 of their 6 simulations, nor are the tT constraints imposed on the models

726 displayed. We annotated the figure to highlight key information necessary for evaluating

727 the model results and the conclusions drawn from them. (F) Simulation \#4 results for

728 sample 01GC89 AHe and AFT dates, with the full swaths of statistically acceptable paths

729 shown as fields. Green boxes on all plots are tT constraints imposed on the models

730 (unknown for Fig. 3D). Simulation \#1-3 results indicate cooling to $<30{ }^{\circ} \mathrm{C}$ by $70 \mathrm{Ma}$, so

731 for reference the intersection of the gray dashed lines marks $30^{\circ} \mathrm{C}$ at $70 \mathrm{Ma}$ on each

732 model output plot. 
Geologic interpretation

Geologic interpretation

--------------------1 - - - - - - - - - - - -

Level 2:

Thermal model outputs, which then can be horizontally integrated with other assumptions and geologic information

Thermal model outputs: Allowed time-temperature paths
Assumptions for interpreting geologic significance of thermal histories (e.g. geothermal gradient, surface temperature)
$-----------1-1$

Level 1:

Thermal model inputs

AHe constraint \#N
(e.g., date, eU, $\mathrm{r}$,
uncertainty)

\section{${ }^{4} \mathrm{He} /{ }^{3} \mathrm{He}$ constraint \#N}

eU zonation

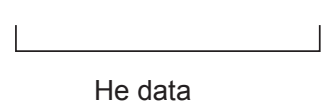

$\downarrow$ \begin{tabular}{l|}
$\begin{array}{l}\text { AFT constraint \#N } \\
\text { (e.g., date, } \\
\text { uncertainty) }\end{array}$ \\
\hline
\end{tabular}

\section{FTL distribution} \#N

Apatite chemical or kinetic data
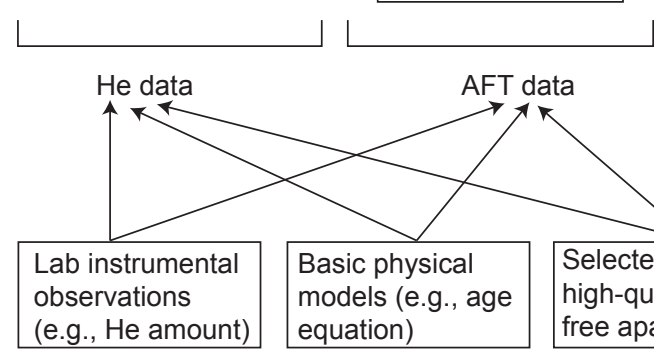

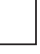

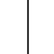

\section{AFT data}
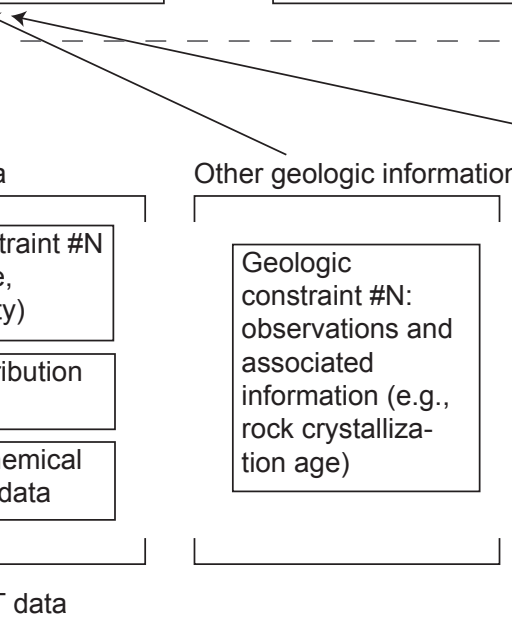

\section{Geologic} constraint \#N: observations and associated information (e.g., rock crystallization age)

$$
\text { tion age }
$$

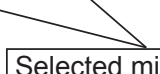

Selected minerals appropriate for high-quality analysis (e.g., inclusionfree apatites for He dating)

Flowers et al.

Figure 1 

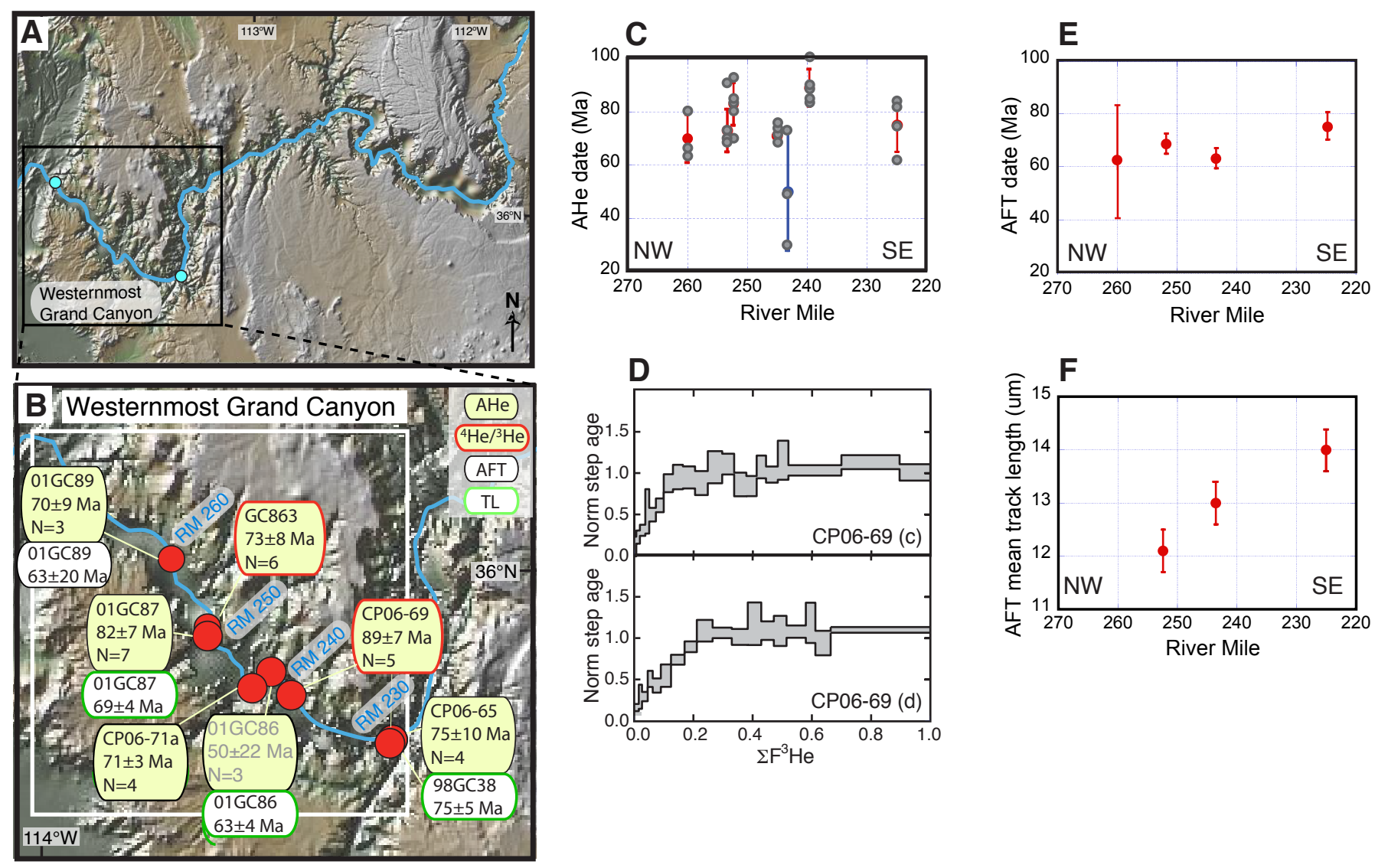

Flowers et al.

Figure 2 

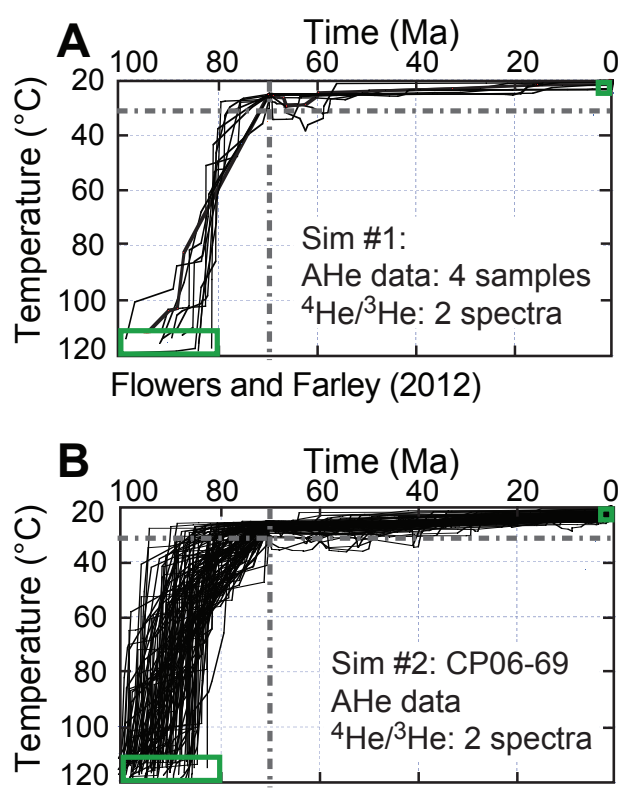

Flowers and Farley (2013)

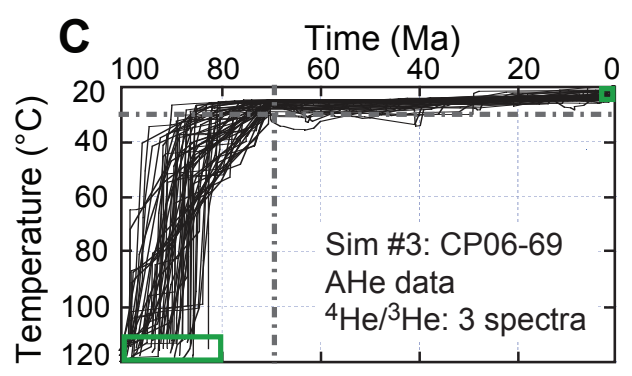

Flowers and Farley (2013)
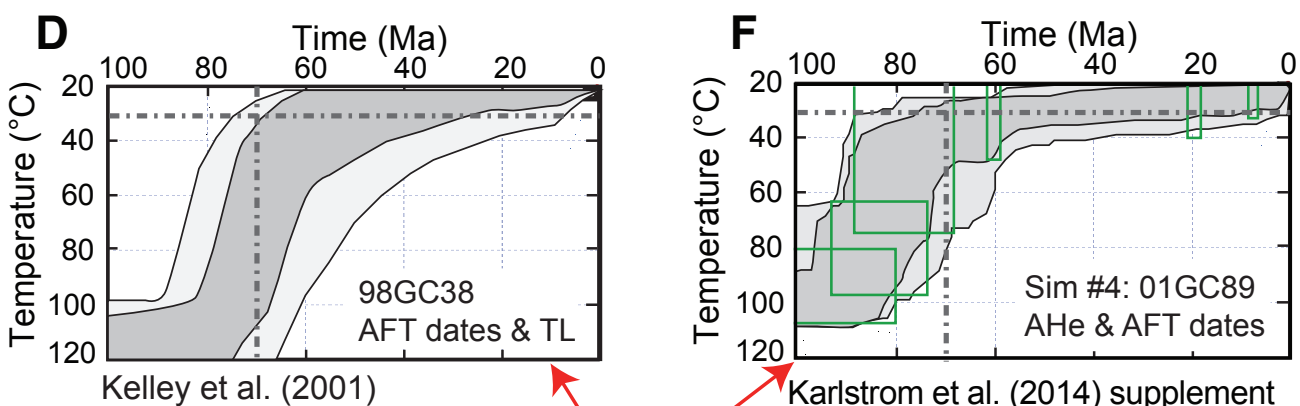

E

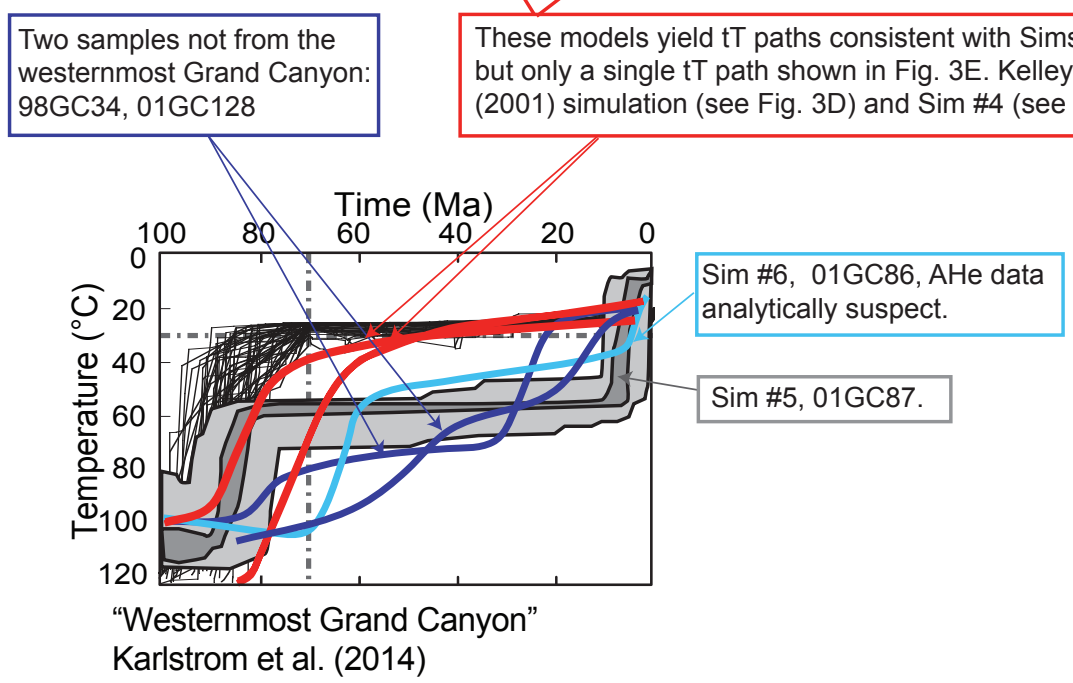

Flowers et al.

Figure 3 


\section{Table 1. Thermal History Model Input Table}

\section{Thermochronologic data}

(U-Th)/He data

${ }^{4} \mathrm{He} /{ }^{3} \mathrm{He}$ data

AFT data

Track length data

If data not presented in another table in paper, cite a specific data table in a reference

All data necessary for modeling must be reported (e.g. $4 \mathrm{He} / 3 \mathrm{He}$ spectra steps, single grain AFT dates, individual track lengths)

Must include all necessary ancillary data that is used in the modeling (e.g., eU zonation, wt\% $\mathrm{Cl}$ ). When not available N/A should be reported and the default assumption in the model spelled out

Describe the uncertainties applied

If data from single or multiple samples are combined, explain how

\section{Additional geologic information}

Assumption (e.g., unconformity, max heating from independent burial depth estimate)

Explanation for the assumption

Source of information for this assumption

\section{System- and model-specific parameters}

He kinetic model (e.g., RDAAM)

FT annealing model: Model assumed, whether c-axis projection applied

Statistical fitting criteria: What constitutes a "good fit"what criterion is used for evaluating fit quality, what are the threshold levels, different methods may have different criteria and thresholds

Modeling code: specific code used and version \#

Number of tT paths attempted 
Table 2. Thermal History Model Input Table for Flowers and Farley $(2012,2013)$ simulations of Westernmost Grand Canyon thermochronology data

\section{Thermochronologic data}

Samples and data used in simulations

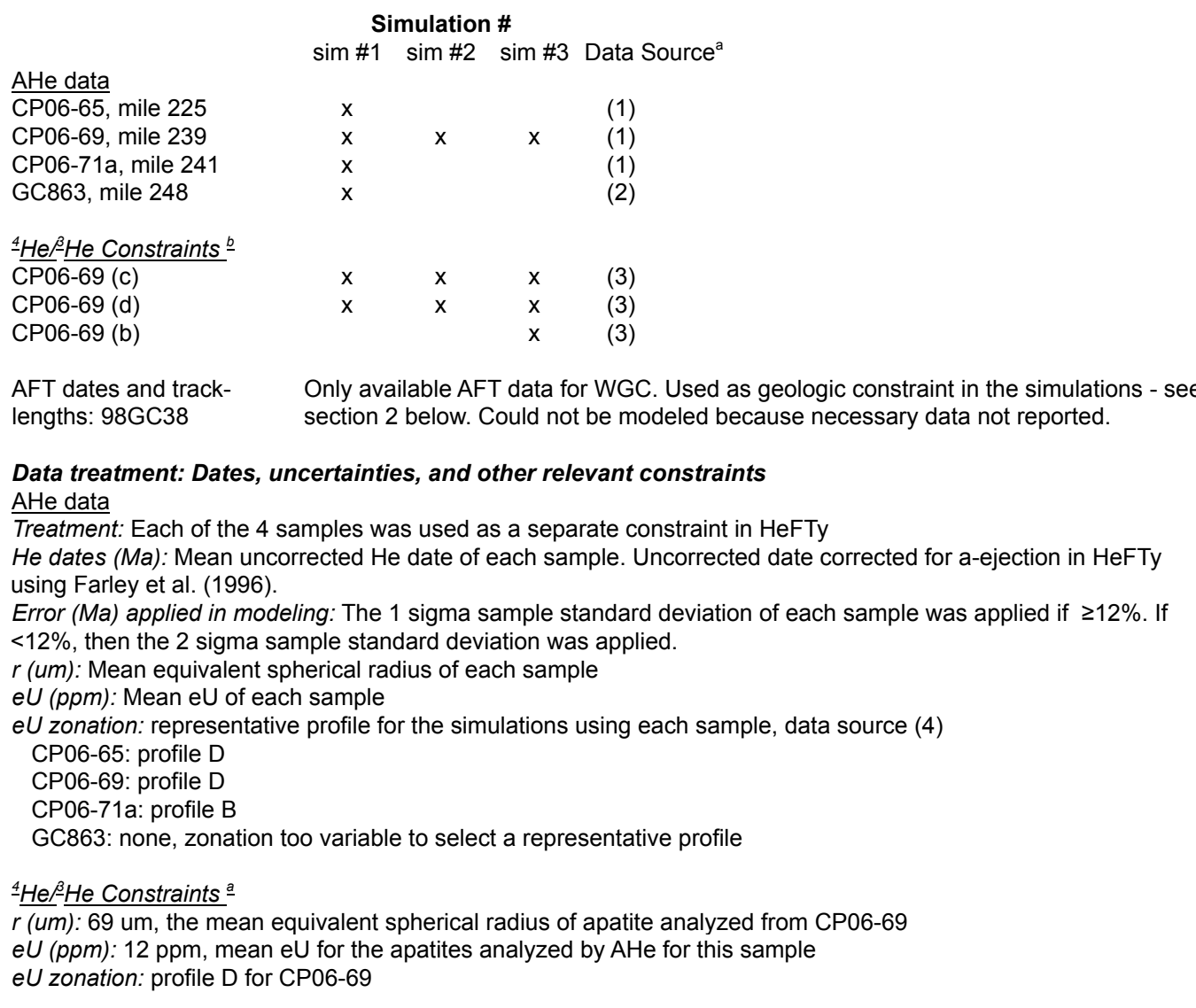

\section{Additional geologic information}

\section{Assumption Explanation and data source}

At surface temperature of $25^{\circ} \mathrm{C}$ based on modern shallow borehole data (Wernicke, 2011, Figure 11). 20 ${ }^{\circ} \mathrm{C}$ is 20-25 ${ }^{\circ} \mathrm{C}$ by $0 \mathrm{Ma} \quad$ probable endmember minimum estimate.

Peak temperature occurred Assumes peak temperature was attained near the timing of maximum burial. at $100-80 \mathrm{Ma}$ Cretaceous units preserved regionally in northern Arizona indicate that deposition continued until $\sim 85 \mathrm{Ma}$ (Nations, 1989; Flowers et al., 2008), consistent with peak burial attainment by that time. Increase to a broader, more conservative age range.

Simulations begin at peak Available AFT data for the Grand Canyon, including the westernmost Grand Canyon, temperatures of 120-110 indicated complete apatite annealing at peak temperatures of $>110^{\circ} \mathrm{C}$ (Dumitru et al., ${ }^{\circ} \mathrm{C}$ 1994; Kelley et al., 2001).

\section{System- and model-specific parameters}

He kinetic model: RDAAM for both $\mathrm{AHe}$ and ${ }^{4} \mathrm{He} /{ }^{3} \mathrm{He}$ simulations

Statistical fitting criteria: GOF values $>0.3$ for $\mathrm{AHe}$; GOF values $>0.32$ for $4 \mathrm{He} / 3 \mathrm{He}$

Modeling Code: AHe uses HeFTy v1.8; ${ }^{4} \mathrm{He} /{ }^{3} \mathrm{He}$ uses Caltech code (unpublished)

Number of $t T$ paths attempted: 8000 for all

\section{Data Source:}

(1) - Flowers et al. (2008), Table DR1

(2) - Flowers and Farley, 2012, Table S6

(3) - Flowers and Farley (2012), Table S2

(4) - Flowers and Farley, (2012), Table S4

b(b),(c ),(d) are individual spectra for separate crystals from the sample 
Table 3. Thermal History Model Input Table for Karlstrom et al. (2014) simulations of Westernmost Grand Canyon Thermochronology Data

\section{Thermochronologic data}

Samples and data used in simulations

\begin{tabular}{clll}
\multicolumn{2}{c}{ Simulation \# } & Data & All data needed \\
$\operatorname{sim} \# 4$ & $\operatorname{sim} \# 5 \quad \operatorname{sim} \# 6$ & Source $^{\text {a }}$ & for modeling published?
\end{tabular}

AHe data

01GC86, mile 243

01GC87, mile 252

01GC89, mile 260

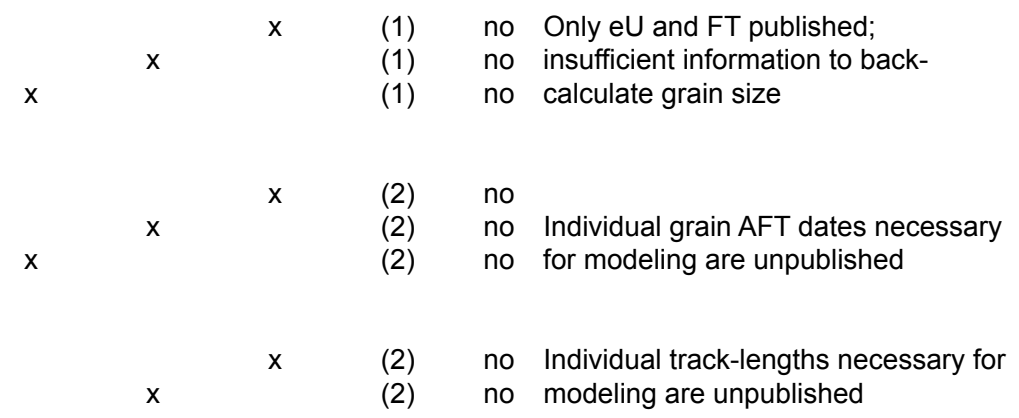

AFT dates

01GC86, mile 243

01GC87, mile 252

01GC89, mile 260

(2) no modeling are unpublished

Data treatment: Dates, uncertainties, and other relevant constraints

AHe data

Treatment: Each apatite analysis modeled independently but simultaneously for each sample, except for sample 01GC86, in which data for three grains is averaged.

He dates (Ma): Indicates that the "group average" is used, but also states each apatite analysis modeled individually. Uncorrected date corrected for $\alpha$-ejection in HeFTy using Farley et al. (1996). Choice of grains modeled for $01 \mathrm{GC} 87$ is not indicated.

Error (Ma) applied in modeling: Unclear. Indicates that the error is the standard deviation of the age group, but one or two sigma not indicated.

$r(u m)$ : Equivalent spherical radius of each grain or grains

$\mathrm{eU}(\mathrm{ppm})$ : The eU of each analysis, or average

AFT data

Cl wt \%: $0.1 \%$

Initial mean track length: 16.17 um

Track length reduction standard: 0.893

\section{Additional geologic information}

\section{Assumption}

Peak temperature occurred in Cretaceous at $\leq 110^{\circ} \mathrm{C}$ for most samples

Paleozoic near-linear increase toward max

temperature

Simulations begin at $500 \mathrm{Ma}$ Represents near surface exhumation of basement samples before deposition of Cambrian Tapeats Sandsone.

\section{System- and model-specific parameters}

He Kinetic model: RDAAM

FT annealing model: Not indicated

FT c-axis projection: Not indicated

Modeling Code: HeFTy v1.7.4

Statistical fitting criteria: Default HeFTy values. GOF values $>0.05$ are acceptable fits. GOF values $>0.5$ are good fits.

Number of $t T$ paths attempted: Following an initial simulation with $>100,000$ paths, additional tT constraints are imposed, and another simulation carried out. Variable attempted paths in the second model.

Data Source:

(1) - Lee et al. (2013), Supplemental File 1

(2) - Lee et al., (2013), Table 2 